\title{
Gasoline Particulate Filter (GPF) Expansion/Contraction Pressure Losses
}

\author{
Ojimah Abel
}

\begin{abstract}
Emission control strategies are required for continuous increase in gasoline direct Injection (GDI) engines, in view of the new legislation control requirements for the implementation of particle number (PN) and particulate matter (PM). Gasoline particulate filter (GPF) is one of the components that can be used to achieve this emission reduction in particulate matter. The flow of gasses across the gasoline particulate filter (GPF) inan exhaust is accompanied by the contraction/expansion pressure losses which has significant effect on the mechanical efficiency of the engine due to back pressure. Flow rate and pressure loss across the monolith- an exhaust operating conditions- are functions of the exhaust gas distribution.
\end{abstract}

This paper is aimed at investigating the expansion /contraction pressure losses in GPFs at different Reynolds number from 200 to 2000 which is enough to keep the flow within the laminar regime for samples of different lengths $305 \mathrm{~mm}$, 250mm and $200 \mathrm{~mm}$.

Pressure tapings were located at the upstream and downstream of the test sample representing the filter scaled up channels to measure the inlet and outlet pressures, and finally, four (4) pressure tapings located along the test sample to capture the respective pressures at each point. These pressure measurements were taken for a 'flow through' of $0.5 \mathrm{~g} / \mathrm{s}$ to $4.7 \mathrm{~g} / \mathrm{s}$ which corresponds to the Reynolds numbers from 200 to 2000. The result highlighted the following silence points: Total pressure losses increase with an increase in mass flow rates. The exit (expansion) pressure losses are 2.5 times higher than the entrance (contraction) pressure losses when compared with ' 2 times higher' prediction recorded in [1] and it varies across the flow rates for the test samples studied.The contraction/expansion pressure drop along the filter is sensitive to the filter length as well as the number of channels in the filter. The inertia loss coefficients are approximately the same for the filters studied.

Index Terms - Emission control, gasoline direct Injection, gasoline particulate filter .

\section{INTRODUCTION}

The control of emission of particulate matter (PM) and oxide of Nitrogen $\left(\mathrm{NO}_{\mathrm{x}}\right)$ to the environment by automotive users has been a major challenge to the automotive industry globally. This has led to both researchers and automotive industries considering the ways of addressing this complex problem towards reducing greenhouse effect and air pollution by toxic emissions.

The existence of Diesel Particulate Filter (DPF) for over fifteen (15) years in Europe and about ten (10) years in United States of America (USA) has proven to be effective in removing particulate emissions. However, the widespread usage of Gasoline Direct Injection (GDI), tight legislation towards reducing particulate mass (PM) and particulate number (PN) standards by the USA, Europeans and Chinese governmenthas prompted the introduction of gasoline particulate filters (GPF)[2].

An additional challenge in the use of particulate filters to reduce the emission of PMs - about $0.01 \mu \mathrm{m}$ to more than $1000 \mu \mathrm{m}$ particle size - is maximising the effective operation of an automotive engine to minimise back pressure [3]. As the back-pressure level increases, the exhaust gases have to be compressed by the engine to a higher pressure which demands additional mechanical work. This affects the intake manifold boost pressure as less energy is extracted by the exhaust turbine. Due to the effect of this back pressure, the need to investigate pressure losses $(\Delta \mathrm{P})$ across the particulate filter is very important to maximise the efficiency, fuel economy and $\mathrm{CO}_{2}$ emissions by automotive engine.

The flows of gasses along square-channels are accompanied by pressure drop due to the frictional losses that exist on the channel walls. These frictional losses $\left(\Delta P_{\text {Friction }}\right)$ are directly proportional to the velocities in the channel for laminar flow [4].The filters collect soot on the wall filter surfaces during the gas flow and causes blockage hence more pressure losses which are proportional to the gas velocity (Darcy losses). Similarly, contraction and expansion losses exist respectively at the inlet and outlet $\left(\Delta P_{\text {Expansion /Contraction }}\right.$ ) of the filter due to the sudden change in area. These $\Delta P_{\text {Expansion /Contraction which are }}$ typically described as inertial losses are directly proportional to the square of the inlet velocities thus contributing significantly to the overall pressure losses in GPFs which operate with high flow rates [1].

\section{COEFFICIENT OF INERTIAL LOSSES IN CONTRACTION/EXPANSION}

Contraction and expansion losses occur whenever there is change in cross-sectional area of a flow. There is generally flow separation as it passes through an obstruction which generates eddies believed to be the cause of the expansion and contraction pressure drops [5]. However, these pressure losses are to be accounted for to maintain the flow rate across the GPF to minimise backpressure and subsequent fuel economy and efficiency of the engine.

A typical pressure distribution in contraction as shown in Fig. 1 for a square edge entrance, has a net effect of loss coefficient approximately equals to $K_{l}=0.5$. This means that one- half of the velocity head is lost as the fluid enters the pipe. 


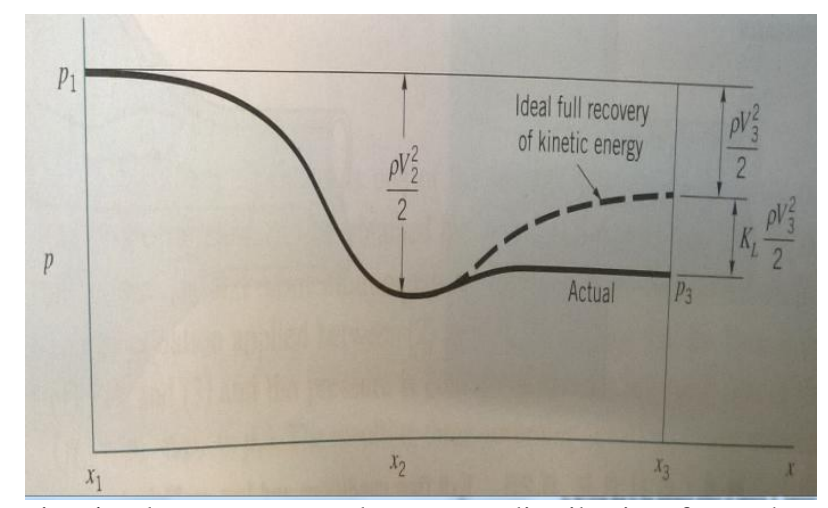

Fig. 1. Flow pattern and pressure distribution for a sharp edge entrance [6].

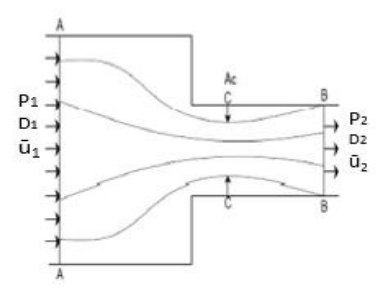

a)

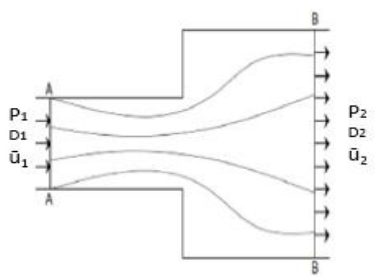

b)
Fig. 2. a) Sudden contraction geometry and b) Sudden expansion geometry [7]

Considering the contraction geometry as shown in Fig. 2, where $D_{1}, \bar{u}_{1}$ and $P_{1}$ represents diameter, mean flow velocity and pressure at point 1 (A-inlet) respectively and $D_{2}, \overline{\mathrm{u}}_{2}$ and $\mathrm{P}_{2}$ represents diameter, mean flow velocity and pressure at point 2 (B-outlet) respectively. Let $A_{1}$ and $A_{2}$ represent the cross-sectional area at point 1 and 2 respectively. Then mean flow velocities are related by continuity equation as:

$$
A_{1} \overline{\mathrm{u}}_{1}=A_{2} \overline{\mathrm{u}}_{2}
$$

Applying momentum equation between point 1 and 2 we have:

$$
\begin{gathered}
P_{1} \mathrm{~A}_{1}+P_{1}\left(\mathrm{~A}_{2}-A_{1}\right)-P_{2} \mathrm{~A}_{2}=A_{2} \overline{\mathrm{u}}_{2} \rho\left(\overline{\mathrm{u}}_{2}-\overline{\mathrm{u}}_{1}\right)(2) \\
\left(P_{1}-P_{2}\right) \mathrm{A}_{2}=A_{2} \overline{\mathrm{u}}_{2} \rho\left(\overline{\mathrm{u}}_{2}-\overline{\mathrm{u}}_{1}\right) P_{1}-P_{2} \\
=\overline{\mathrm{u}}_{2} \rho\left(\overline{\mathrm{u}}_{2}-\overline{\mathrm{u}}_{1}\right)(3)
\end{gathered}
$$

Applying the Bernoulli's equation between point 1 and 2 adding head loss $\left(h_{L}\right)$ we have:

$$
\frac{P_{1}}{\rho g}+\frac{\overline{\mathrm{u}}_{1}^{2}}{2 g}+Z_{1}=\frac{P_{2}}{\rho g}+\frac{\overline{\mathrm{u}}_{2}^{2}}{2 g}+Z_{2}+h_{L}(4)
$$

Here:

$Z_{1}$ and $Z_{2}$ : Pipe height at point 1 and 2 respectively. $\rho:$ Density of the gas.

$g$ : Acceleration due to gravity.

For horizontal pipe, $Z_{1}=Z_{2}$

Therefore equation (4) can be written as:

$$
h_{L}=\frac{P_{1}-P_{2}}{\rho g}+\frac{\overline{\mathrm{u}}_{1}^{2}-\overline{\mathrm{u}}_{2}^{2}}{2 g}
$$

Substituting equation (3) into (5) we have:

$$
h_{L}=\frac{\overline{\mathrm{u}}_{2} \rho\left(\overline{\mathrm{u}}_{2}-\overline{\mathrm{u}}_{1}\right)}{\rho g}+\frac{\overline{\mathrm{u}}_{1}^{2}-\overline{\mathrm{u}}_{2}^{2}}{2 g}=\frac{\left(\overline{\mathrm{u}}_{1}-\overline{\mathrm{u}}_{2}\right)^{2}}{2 g}(6)
$$

From equation (1),

$$
\overline{\mathrm{u}}_{2}=\overline{\mathrm{u}}_{1}\left(\frac{A_{1}}{A_{2}}\right)
$$

Substituting $\overline{\mathrm{u}}_{2}$ into Equation (6) yields:

$$
h_{L}=\frac{\overline{\mathrm{u}}_{1}^{2}}{2 g}\left(1-\frac{A_{1}}{A_{2}}\right)^{2}=\frac{\overline{\mathrm{u}}_{2}^{2}}{2 g}\left(\frac{A_{2}}{A_{1}}-1\right)^{2}
$$

Equation (7) is referred to as Borda- Carnot relation use in accounting for head loss. As recorded in[4], [7], the relationship between pressures drops and head loss in sudden expansion is:

$$
\Delta P_{E x p .}=\zeta_{E} \frac{\rho \overline{\mathrm{u}}_{2}^{2}}{2}
$$

Where,

$\zeta_{E}$ is equal to the expansion correlation factor (coefficient of inertia losses) that depends on Reynolds number $(\mathrm{Re})$ and cross-sectional flow area. It is used to account for the effect of ejection on a square cross-sectional channel [1].

Considering Fig. 2a, momentum equation cannot be applied between point 1 and 2 because of the non-uniformity of the pressure distribution [5]. However, experiments have indicated that eddies are the cause of the pressure loss which takes place between point $\mathrm{C}$ and 2. Contraction losses can be worked out by considering equation (8) such that $A_{c}$ is the area at the vena contracta (based on smaller entry diameter at point $\mathrm{C}$ ). Applying sudden expansion loss expression between $A_{c}$ and $A_{2}$ we have:

$$
h_{L}=\frac{\overline{\mathrm{u}}_{2}^{2}}{2 g}\left(\frac{A_{2}}{A_{c}}-1\right)^{2}=\frac{\overline{\mathrm{u}}_{2}^{2}}{2 g}\left(\frac{1}{C_{c}}-1\right)^{2}(9)
$$

where,

$C_{c}$ is coefficient of contraction due to inlet entry small diameter.

Equation (9) can be written in the form:

$$
h_{L}=K \frac{\overline{\mathrm{u}}_{2}^{2}}{2 g}
$$

The expression in bracket in equation (9) is constant for any given area ratio. Hence, $\mathrm{K}$ is Loss coefficient equal to 0.5 for a sharp pipe entry and exit [10].

Therefore, the pressure drop due to sudden contraction is expressed as:

$$
\Delta P_{\text {Cont }}=\zeta_{c} \frac{\rho \overline{\mathrm{u}}_{2}^{2}}{2}
$$

where,

$\zeta_{c}$ is equal to the contraction correlation factor (coefficient of inertial losses) that depends on Re and cross-sectional flow area. It is used to account for the effect of suction on a square cross-sectional channel [9].

Various values of contraction and expansion coefficients have been reported in the literature for 
example,Contraction/expansion losses were cited in [10] as:

$$
\begin{aligned}
\Delta P_{\text {Cont } .}= & \frac{\rho \overline{\mathrm{u}}_{2}^{2}}{4}(12) \\
& \text { And } \\
\Delta P_{\text {Exp. }}= & 1.098 \frac{\rho \overline{\mathrm{u}}_{2}^{1.919}}{2}\left[1-\left(\frac{A_{\text {open }}}{A_{\text {tot al }}}\right)\right]^{1.919}
\end{aligned}
$$

Applying the above equations for DPFs of the area ratio of 0.35 the inertial coefficient $\left(\zeta=\zeta_{E}+\zeta_{C}\right)$ is equal to 0.67 .

Due to different open area fraction (OAF), different length, wall thickness and channel sizes for different filters, mass flow rate, the estimated expansion/contraction inertia losses coefficient from DPFs simulation paper shows no consistency in the values of $\zeta,[4],[9],[11]$ therefore, further experiments need to be conducted to obtain reliable values of $\zeta$.

In all literature, there are variations of Darcy permeability ( $\mathrm{K}$ value) even with the same filter, believed to be over estimation of filtration area during the analysis of pressure drop versus flow rate, other losses due to permeability, sample quality variation, experimental error among other factors.Contraction pressure drops occur at a distance into the filter from the entrance point but, no existing experiment to estimate the length at which it occurs. Also, most of the research are based on DPFs and little or no experiments have been conducted on gasoline particulate filters (GPFs) expansion/contraction losses, even though these losses are more important because they grow as square of the mean velocity. Considering the gasoline direct injection (GDI) technology, the need for this paper cannot be over emphasised.

Specifically, this paper aims to

- Measure pressure losses in several "flow through" samples of different length and contraction/expansion ratios

- Investigate the effect of the channel diameter on the pressure drop across the sample

- Investigate the effect of sample length on pressure drop across the sample

- Investigate the effect of open frontal area on the pressure drop across the sample

Experimental validation was performed on GPFs to obtain the contraction / expansion losses and compared with the theoretical calculation of which the result shows an underestimation of $17 \%, 10 \%$ and $23 \%$ for samples $300 / 12$ $\mathrm{N}=13,300 / 12 \mathrm{~N}=12$ and $300 / 8 \mathrm{~N}=12$ respectively; the coefficient of friction was obtained. The experimental methodology is described in the following order: test samples, experimental setup, and procedure.

\section{TEST SAMPLES}

A 3 D cell- channel model was designed as a test sample to represent gasoline particulate filter and used for this experimental measurement. The geometry, CAD design and picture of $3 \mathrm{D}$ printing for the test samples are shown in Fig. 3 $\mathrm{a}, \mathrm{b}$, and c respectively.

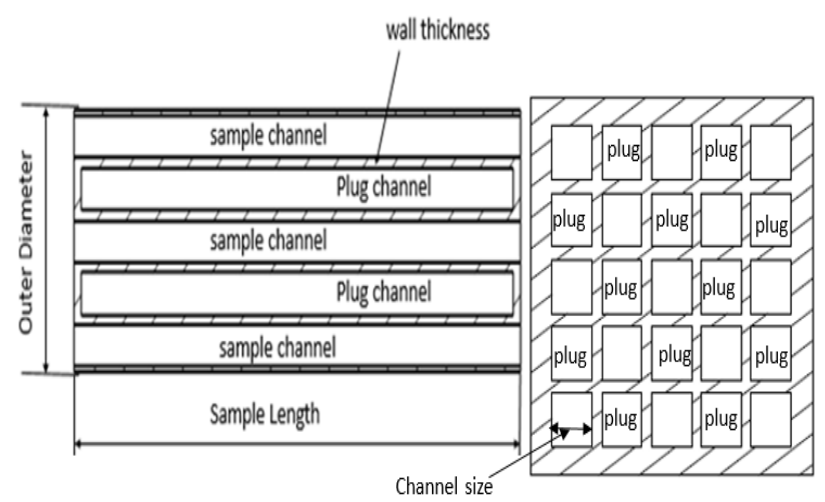

Fig.3 a. Test sample geometry.

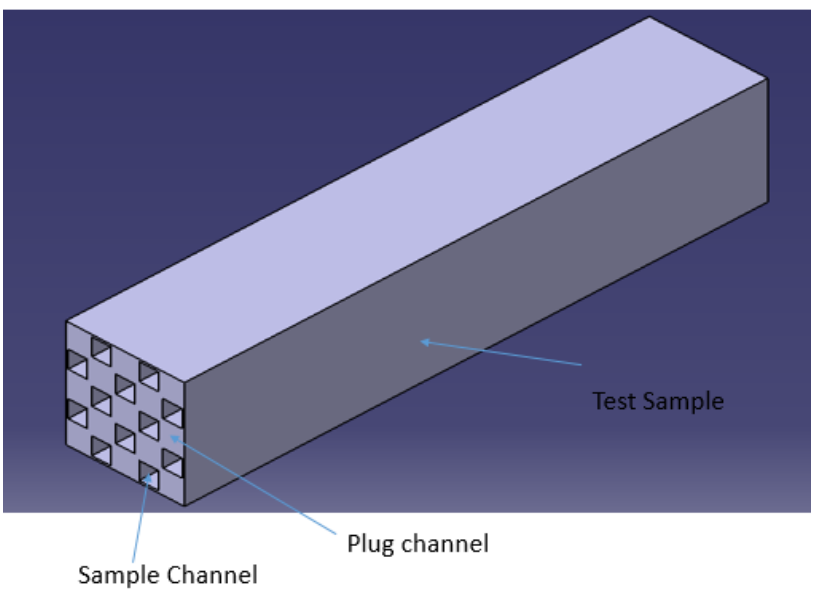

Fig. 3 b. CAD for the Test Sample
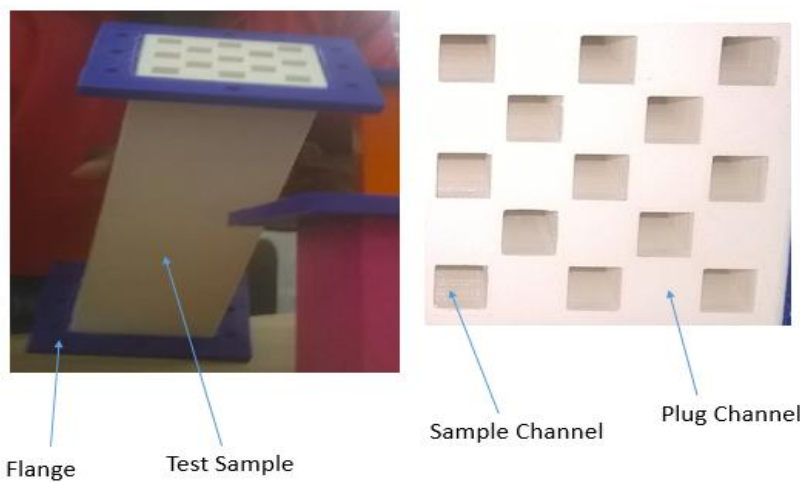

Fig. 3 c. photograph of Test Sample.

Nine test samples were designed for different wall thickness that corresponds to the scaled-up channels of a filter as shown in Table 3 . The relations in equations 14, 15 and 16 were used respectively.

Given a, as channel size, $\mathrm{w}_{\mathrm{s}}$ as wall thickness, $\sigma$ as cell density, $b$ as the effective width, $\mathrm{N}_{\text {cell }}$ is number of cells for the test sample. Therefore,

Channel width, $\mathrm{a}=\frac{1}{\sqrt{\sigma}}-\mathrm{w}_{\mathrm{s}}$,

Let, $\frac{1}{\sqrt{\sigma}}=a_{\text {Total }}$,

Therefore, $N_{\text {cells }}=\frac{b}{a_{\text {Total }}}$

The open Fraction ratio (OFA) is calculated using equation (20) as:

$$
\mathrm{OFA}=0.5\left(1-\frac{w_{s}}{a_{\text {Total }}}\right)
$$


The test samples CAD designs parameters used are shown in table 1.

Table 1. Parameter used for Test Sample Design

\begin{tabular}{|c|c|c|c|}
\hline $\begin{array}{r}\text { Filter schaled-up } \\
\text { channel }\end{array}$ & $\begin{array}{l}300 / 12 \\
\mathrm{~N}=13\end{array}$ & $2^{300 / 1}$ & $\begin{array}{l}300 / 8 \\
\mathrm{~N}=12\end{array}$ \\
\hline Wall Thickness (mm) & 2.4 & 2.4 & 1.6 \\
\hline OFA $(\%)$ & 33 & 33 & 38 \\
\hline $\begin{array}{l}\text { Channel Diameter } \\
(\mathrm{mm})\end{array}$ & 10 & 10 & 10.8 \\
\hline Outer Diameter (mm) & 62 & 62 & 62 \\
\hline Length (mm) & $\begin{aligned} A & = \\
305 & \\
B & = \\
250 & \\
C & = \\
200 & \end{aligned}$ & $\begin{array}{r}\mathrm{D} \\
305 \\
\mathrm{E} \\
250 \\
\mathrm{~F} \\
200\end{array}$ & $\begin{aligned} G & = \\
305 & \\
H & = \\
250 & \\
I & = \\
200 & =\end{aligned}$ \\
\hline
\end{tabular}

\section{EXPERIMENTAL SETUP}

Fig. $4 \mathrm{a}$ and $\mathrm{b}$ shows the schematic and the photograph of the experimental setup for the sample measurements.

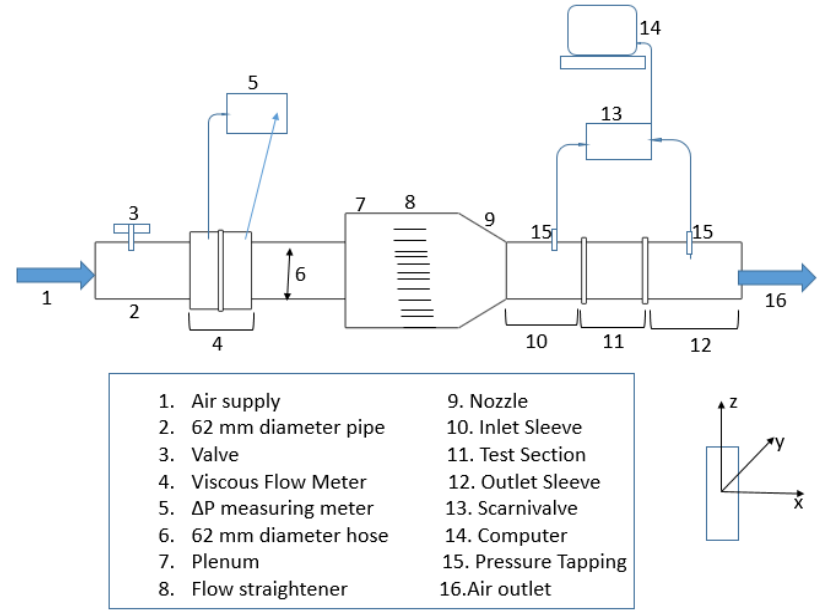

a) Schematic Diagram

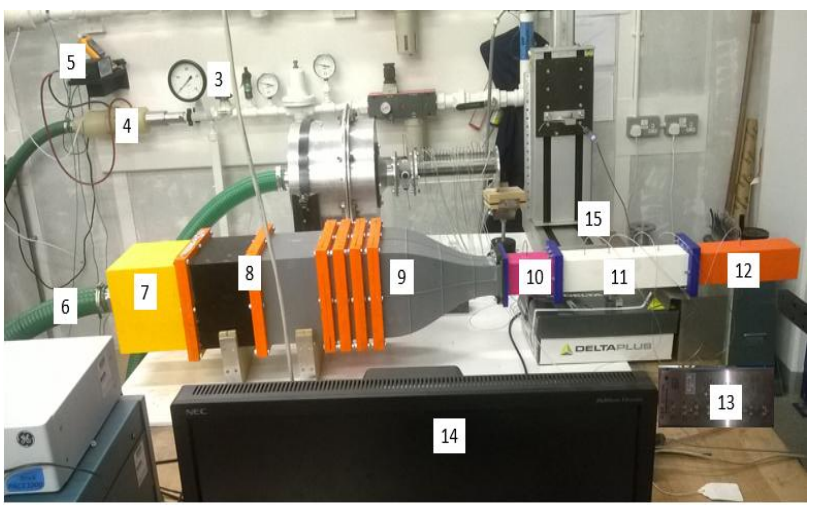

b) Photograph

Fig.4: Experimental Flow Rig; a) Schematic, b) Photograph; $x$ and $Z$ are Nozzle Outlet plane

The experimental rig used is the Coventry University flow laboratory (CFL) rig with improved modification at section 7 , 8 and 9 by Mr Marco Prantoni a Phd student at Coventry University. The experimental rig has a valve (3) used in regulating the flow rate during the experimental measurements. Section 4 which is the Viscous flow meter
(VFM) located upstream of the flow rigs after the valve, was used to determine the mass flow rate. The pressure drop $(\Delta \mathrm{P})$ across the VFM was measured using Digital Manometer (5) in the rig. This was possible due to the multi- channel monolith inside the VFM which generate pressure difference as the flow goes across. For fully developed laminar flow, the mass flow rate is directly proportional to pressure drop as shown in equation 17 (Hagen - Poiseieulle).

$$
\frac{\Delta P_{m}}{L}=2 f R e_{c} \frac{\square U_{c}}{d_{h}^{2}}
$$

Where,

$d_{h}$ : Hydraulic diameter $(\mathrm{m})$

$\Delta P_{m}$ : Pressure drop across the monolith due to fully developed flow $(\mathrm{Pa})$

L: Length of the monolith $(\mathrm{m})$

$\mu$ : Dynamic viscosity of fluid $(\mathrm{Kg} / \mathrm{m} \mathrm{s})$

$\overline{\mathrm{u}}_{c}$ : Mean channel velocity $(\mathrm{m} / \mathrm{s})$

$f R e_{c}$ : Frictional forming factor for fully developed flow.

For a square nozzle of cross-sectional area (A), if the velocity through the nozzle outlet is $\overline{\mathrm{u}}$, and the density $(\rho)$, the mass flow rate (m) in $\mathrm{Kg} / \mathrm{s}$ is:

$$
\dot{\mathrm{m}}=\rho \overline{\mathrm{u}} \mathrm{A}
$$

Therefore, for multiple channel flow such that the velocity of each of the channel is represented by $\overline{\mathrm{u}}_{c}$ and the area of each of the channel is $A_{c}$, the mass flow rate of the channel $\left(\dot{\mathrm{m}}_{c}\right)$ is:

$$
\left(\dot{\mathrm{m}}_{c}\right)=\rho \overline{\mathrm{u}}_{c} \mathrm{~A}_{\mathrm{c}}
$$

Similarly, the total mass flow rate $\left(\dot{\mathrm{m}}_{\text {Total }}\right)$ is:

$$
\left(\dot{\mathrm{m}}_{\text {Total }}\right)=\mathrm{n} \rho \overline{\mathrm{u}}_{c} \mathrm{~A}_{\mathrm{c}}
$$

Where $\mathrm{n}$ is equals to the number of channels.

The flow straightener and nozzle are in 8 and 9 respectively in the flow rig. These allowed the flow to redistribute, developed before approaching the inlet sleeve to provide uniform flow. On the sleeveis pressure tapings (15, Fig.5) used in taping the pressure through the rubber hose channels to the Scanivalve at position 13 in the rig. As can be seen in Fig. 5, six (6) pressure tapings were used for the pressure drop measurements across the test samples so that the pressure variations can be captured reasonably. These are: one pressure taping at the inlet sleeve $64 \mathrm{~mm}$ away from the sample entrance to measure the entrance pressure (P1), one (1) pressure tapping at position 2 which is $68.5 \mathrm{~mm}$ into the test sample to measure the contracta pressure (P3) because Literature has shown that, the actual pressure drop at the entrance takes place a little distance from the filter's entrance [11], three (3) pressure tapings along the test sample at distances $124.5 \mathrm{~mm}, 180 \mathrm{~mm}$, and $236.5 \mathrm{~mm}$ from the sample entrance to capture the pressure variations along position 3, 4, 5 respectively. Finally, one pressure taping is located $123 \mathrm{~mm}$ from the end of sample outlet into the sleeve to measure the exit pressure at P6. The length of the rubber hose channels connecting the pressure taping and scanivalve is $1020 \mathrm{~mm}$ while that of pressure taping is $30 \mathrm{~mm}$. These were recorded, 
World Journal of Innovative Research (WJIR) ISSN: 2454-8236, Volume-5, Issue-3, September 2018 Pages 18-29

to maintain consistency throughout the experimental measurements.

The scarnivalve (13 in Fig.4) can measure the pressure up to 0.5 PSID with the resolution of $0.7 \mu$ pa and has channel 1-16. The computer (14) interfaces with scanivalve with the help of the software to deduce the pressure values. This pressure values are further post processed by taking the average of the pressure measurements at the various tapings for experimental analysis usingthe excel spread sheet.

Before the Testing procedure, detail of the pressure tapings locations $(1,2,3,4,5$, and 6$)$ which were not well captured in the rigis shown in Fig. 5.

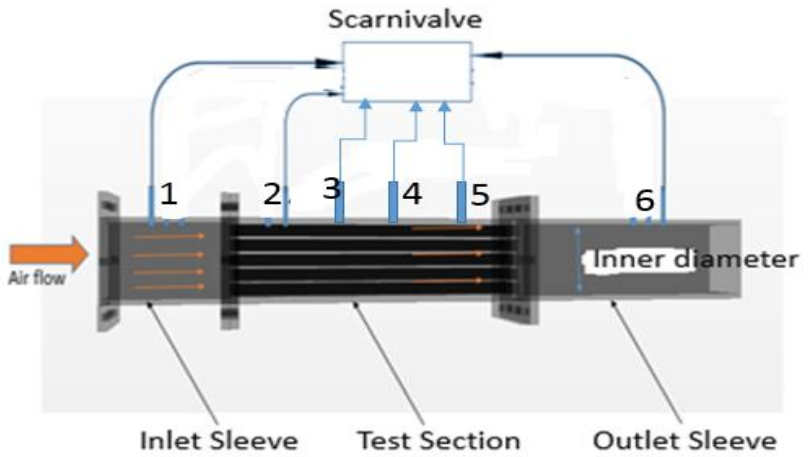

Fig. 5. Fixtures for pressure drop measurements

\section{EXPERIMENTAL PROCEDURE}

Pressure drop was determined for all the three channels samples considered to ascertain change in pressure due to flow rate and mean velocity; then the channel lengths were modified and its effects on contraction / expansion changes was also tested. For better understanding of the various test sample parameters total pressure contribution, an isolated test sample parameter was studied. This was aimed at determining the optimum test sample density as its geometrical attributes were specified. This is very important in practice since design constraints placed restrictions in choosing the length of the filter.

\section{A. Determination of VFM pressure drops}

The samples to be tested were mounted at the test section as shown in Fig. 5. The valve was used to control the dry air that flows through the test sample at different mass flow rate from $0.5 \mathrm{~g} / \mathrm{s}$ to $4.7 \mathrm{~g} / \mathrm{s}$ which corresponds to the VFM pressure drops of $20 \mathrm{~Pa}$ to $370 \mathrm{~Pa}$. The VFM pressure drops were obtained from the calibrated low-pressure line chart shown in appendices A1 using the low Reynolds number of 200 to 2000. As the air passes through the test sample, measurements of the different pressure losses were taken with the help of the scanivalve connected via rubber hose channels that correspond to the individual pressure tapings. The software Scanivalve Tel serves as an interface between the computer and the scanivalve to scan the values of these pressure drops. The setup of the scanivalve software that was used to obtain the experimental data is shown in appendeces A2. Care was taken to monitor the temperature changes throughout the experiment since there was a tendency for temperature rise due to changes in pressure drop and the device supplying the flow. The experiment was conducted at room temperature and was monitored. This was done to minimize temperature changes during the experiment which will affect the pressure drop values and generate further uncertainty needed to be corrected later for accuracy of the experimental results. Dry air was the working fluid. Ideal gas law was used to find the air density.

In practical conditions, design constrains are normally imposed in utilizing smaller filters on cars due to the availability of space. Due to this, the parameter studies were carried out on one of the key parameter, the filter sample length.

B. Estimation of change in pressure drop due to change in length of filter

After the completion of the pressure drop measurements, the filters were then reduced by cutting it and the pressure drop re-measured to ascertain the change in pressure drop with reduction of length. In this procedure, we can be confident that the pressure drop variation of the filter is due to only changes in the length. This approach is promising in the study of the performance of filter in relation to its length.

Following the assumptions that flow through the test sample channel is laminar, incompressible and Newtonian; the following equations were used in predicting the experimental results.

$\dot{\mathrm{m}}_{\text {total }}=\rho \overline{\mathrm{u}}_{\text {channel }} A_{\text {sample }}$

$\overline{\mathrm{u}}_{\text {channel }}=\frac{\dot{\mathrm{m}}_{\text {total }}}{\rho A_{\text {sample }}}$,

Here,

$\overline{\mathrm{u}}_{\text {channel }}$ is mean air velocity in the channel $(\mathrm{m} / \mathrm{s})$

$\dot{\mathrm{m}}_{\text {total }}$ is total mass flow rate $(\mathrm{kg} / \mathrm{s})$

$\rho$ is air density at room temperature $\left(\mathrm{kg} / \mathrm{m}^{2}\right)$

$A_{\text {sample }}$ Open front area of the sample $(0.003844 \mathrm{~m} 2)$

Theoretical prediction of the pressure drops.

From,

$\Delta P_{\text {Total }}=\Delta P_{F r}+\Delta P_{\text {exp } / \text { Cont }}$.

The equation (22) can be written in the form

$\Delta P_{\text {Total }}=\alpha \overline{\mathrm{u}}+\beta \overline{\mathrm{u}}^{2}$,

Here,

$\alpha$ is the coefficient calculated from theoretical frictional losses across the sample $\left(\Delta P_{f r}\right)$.

$\beta$ is the coefficient calculated from expansion /contraction losses $\left(\Delta P_{\text {exp } / \text { con }}\right)$

Uis mean velocity of the channel

The frictional losses $(\alpha)$ can be obtained from Darcy Weisbach equation as:

$\Delta P_{F r}=\rho \mathrm{f} \frac{L}{D} \frac{\overline{\mathrm{U}}^{2}}{2 g}$

Here,

$\mathrm{f}=\frac{64}{R e}$ is the friction factor,

$\rho$ is air density at room temperature as defined earlier

$\frac{L}{D}$ is geometric factor (length to diameter ratio)

$\frac{\overline{\mathrm{U}}^{2}}{2 g}$ is velocity head loss $\left(h_{D}\right)$

$\Delta P_{\exp / \text { Cont } .}=\zeta_{\exp / \text { cont }} \frac{\rho \overline{\mathrm{u}}_{2}^{2}}{2}$ 
Comparing equation (23) with (24) and (25) in the expression we have.

$$
\Delta P_{\text {Total }}=\Delta P_{F r} \overline{\mathrm{u}}+\Delta P_{\text {exp } / \text { Cont }} . \overline{\mathrm{u}}^{2}
$$

\section{RESULTS AND DISCUSSIONS}

A. Influence of pressure losses on flow characteristics

For all the tested samples, it was observed that the total pressure drops increased with the increase in mass flow rate (Fig. 8). However, the pressure losses are different for different filters; this pressure drop is higher for sample A and lowest for sample $\mathrm{C}$ with twenty two percentage (22\%) difference. It equally follows that the total pressure drop is higher for higher number of channels $(\mathrm{N}=13)$ by $41 \%$. There is no clear separation at low mass flow rate below $1.7 \mathrm{~g} / \mathrm{s}$, This trend could be explaining that, at low mass flow rate, the pressure drop is low due to low kinetic energy which does not allow the velocity profile to develop completely whereas at flow rate above $1.7 \mathrm{~g} / \mathrm{s}$, the velocity profile began to develop completely and the separation in the plot are noticed as can be seen in Fig. 8.

C. Raw data (pressure loss Vs flow rate)

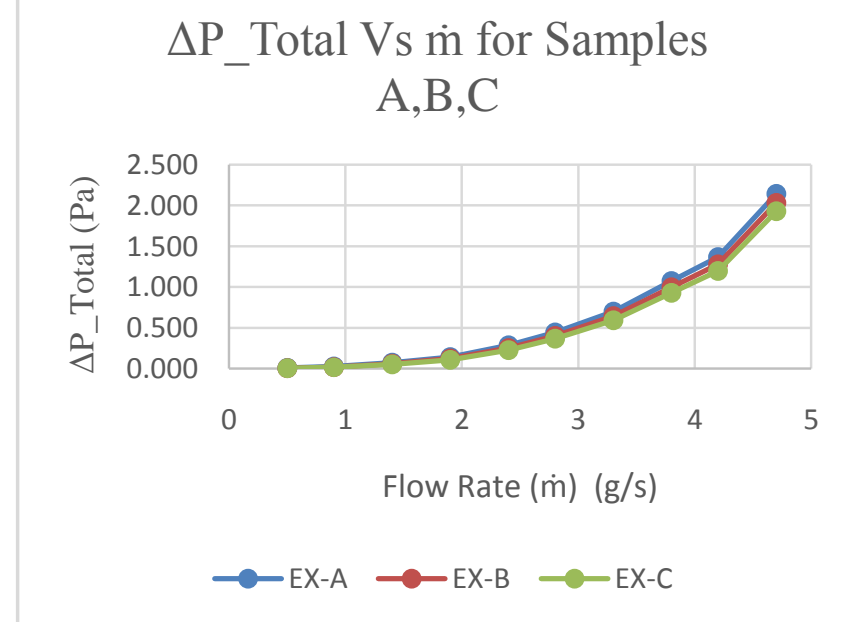

a)

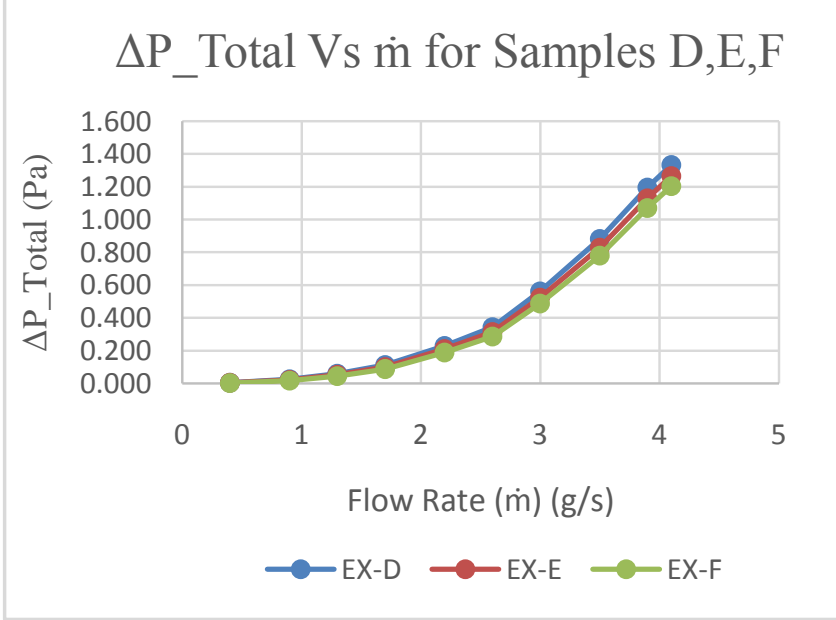

b)

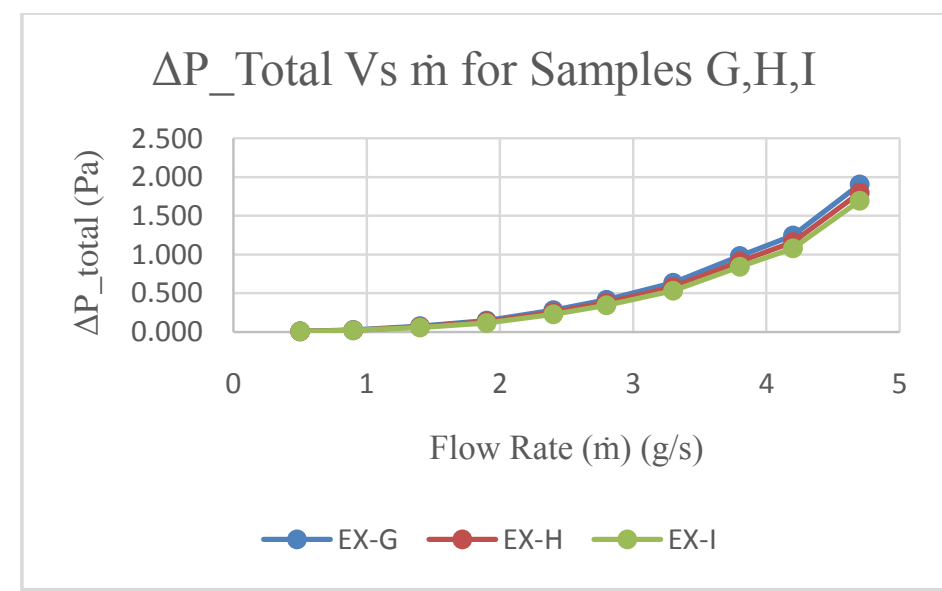

c)

Fig. 8 a, b, c. plot of total pressure drops versus mass flow rates for tested samples (A, B, C, D, E, F, G, H, I)

This has demonstrated that the pressure drop for the test sample is sensitive to the changes in sample length at flow rate above $1.7 \mathrm{~g} / \mathrm{s}$ where the experiment appears feasible which agrees with the work in [12].

\section{Raw data (pressure loss Vs mean velocities)}

\section{pressure drop vs mean velocity}

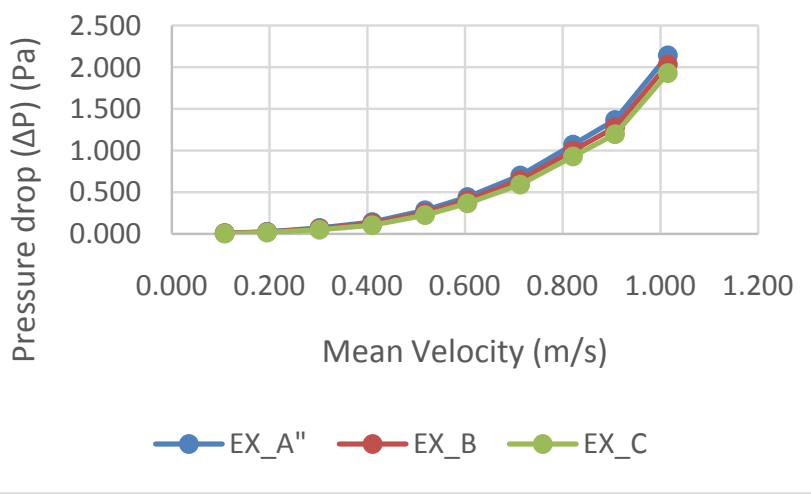

a)

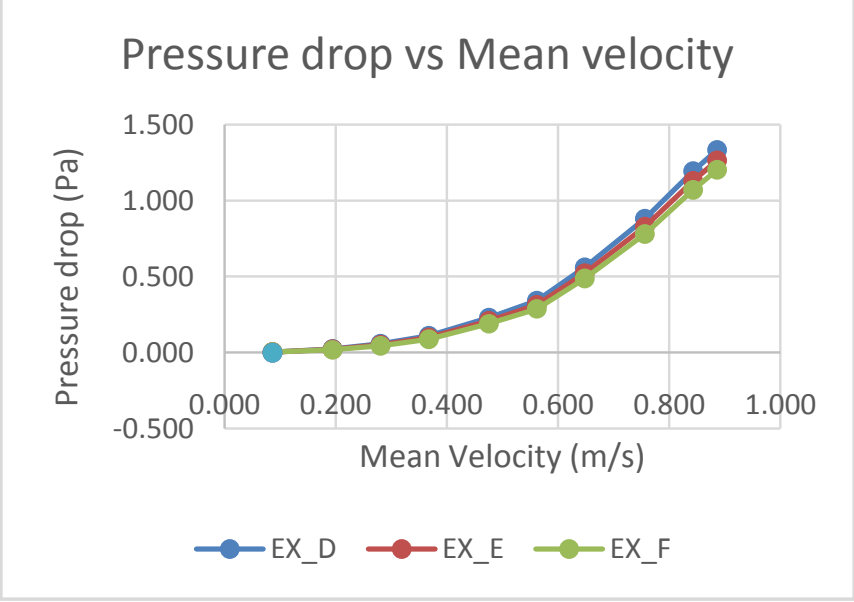

b) 
World Journal of Innovative Research (WJIR)

ISSN: 2454-8236, Volume-5, Issue-3, September 2018 Pages 18-29

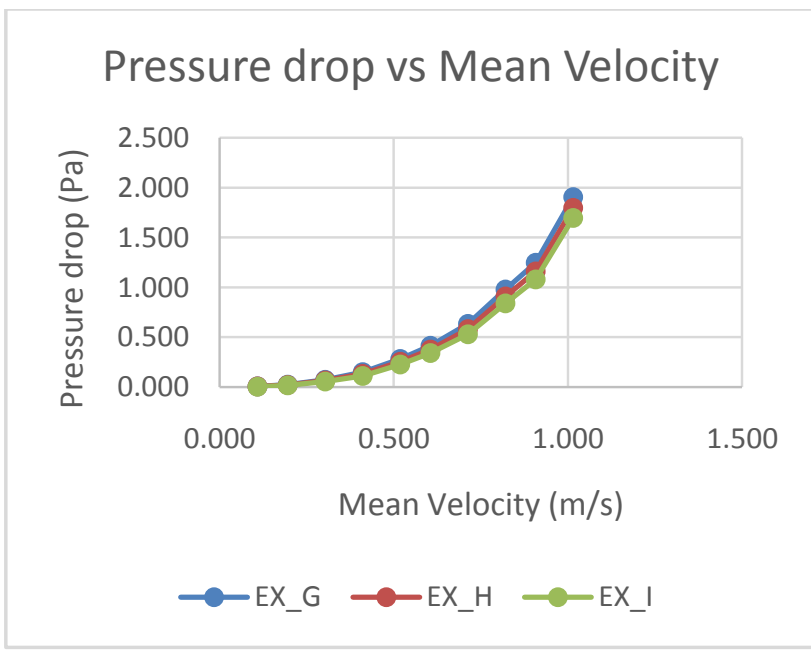

c)

Fig. 9 a, b, c. plot of total pressure drops verse mean velocities for tested samples (A, B, C, D, E, F, G, H, I).

The similar trend as in pressure drops and flow rates is observed for pressure losses and mean velocities for the test samples (Fig.9). At velocity above $0.591 \mathrm{~m} / \mathrm{s}$ the pressure drops increases with square velocity.

E. Comparison of experimental results and theoretical estimations for pressure loss vs mean velocities

The result of the monolith pressure drops was compared with the theoretical calculation obtained from the following equations:

$\Delta P_{\text {Theory }}=\Delta P_{F r}+\Delta P_{\text {exp } / \text { Cont } .}$,

$\Delta P_{L 1}-\Delta P_{L 2}=f \frac{\left(L_{1}-L_{2}\right)}{D} \rho \frac{\overline{\mathrm{u}}^{2}}{2}$

Here, all parameters as defined earlier.

For 300/12, N=13

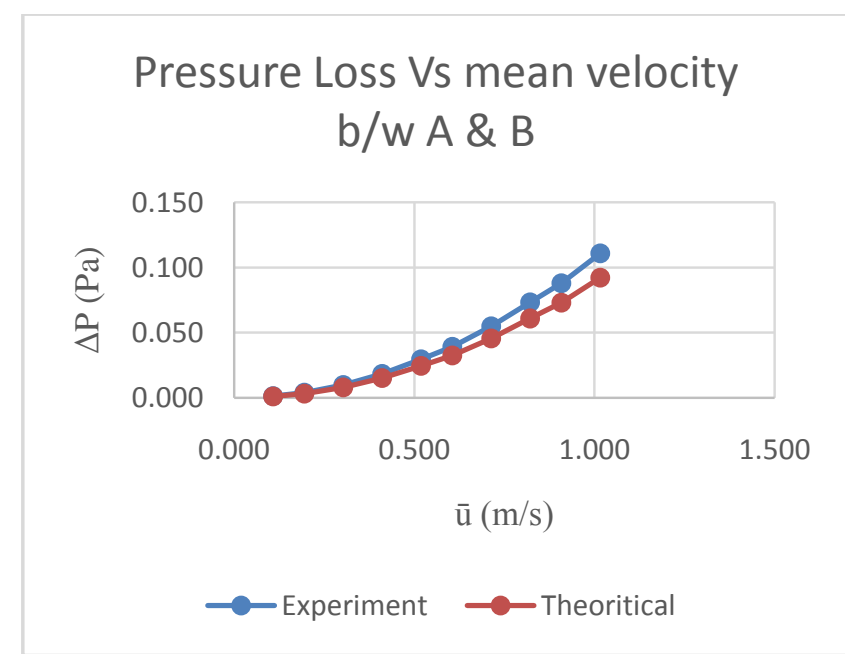

a)

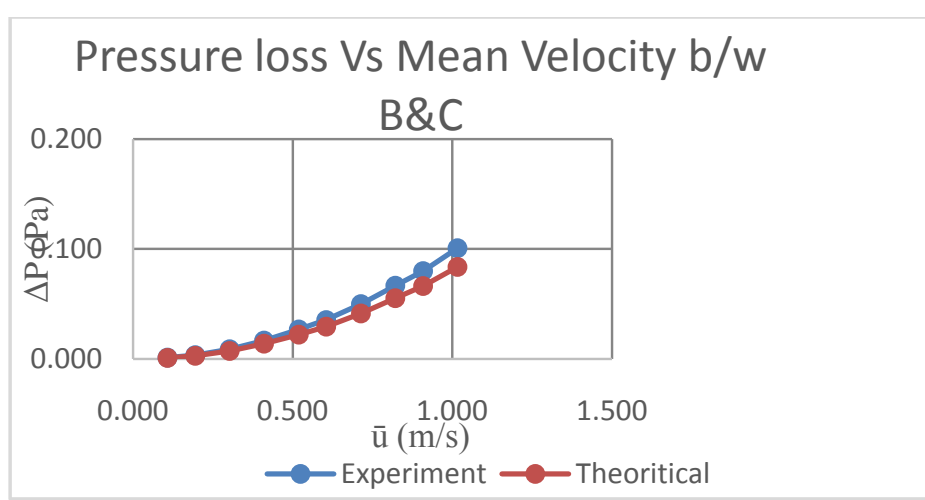

b)

Fig. 10 a, b. Comparison of experimental and theoretical total pressure drops verse mean velocities for test samples length $\mathrm{A}$ and $\mathrm{B}, \mathrm{B}$ and $\mathrm{C}$.

The experiment is under-estimated by $17 \%$

For $300 / 12, N=12$

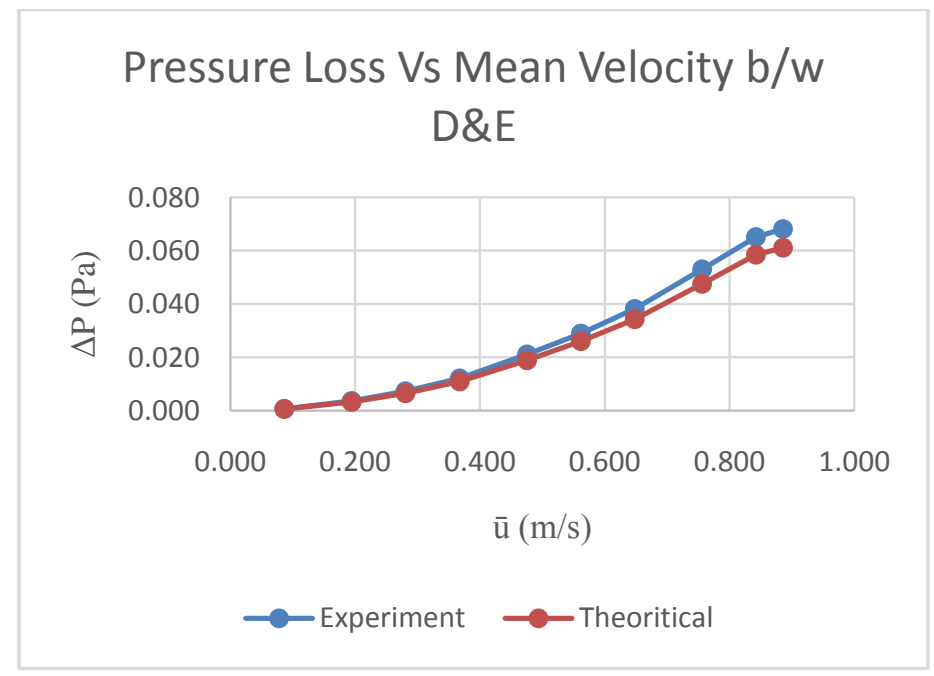

a)

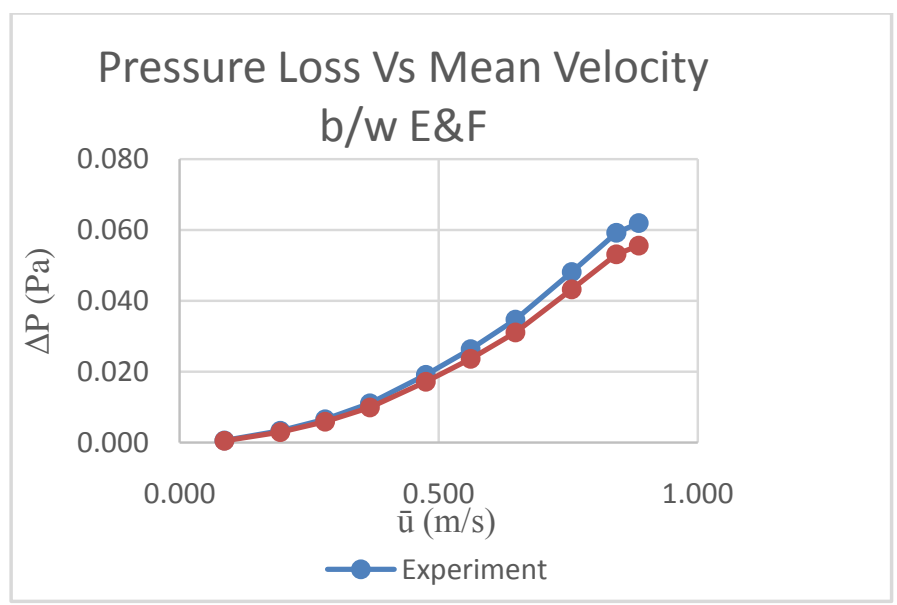

b)

Fig. 11 a, b. Comparison of experimental and theoretical total pressure drops verse mean velocities for test samples length $\mathrm{D}$ and $\mathrm{E}, \mathrm{E}$ and $\mathrm{F}$.

Similarly, it can be observed in Fig. $11 \mathrm{a}, \mathrm{b}$ that the result of the pressure drop between the experiment and theoretical prediction shows that the experiment is under-estimated by $10 \%$. 
For 300/8, N=12

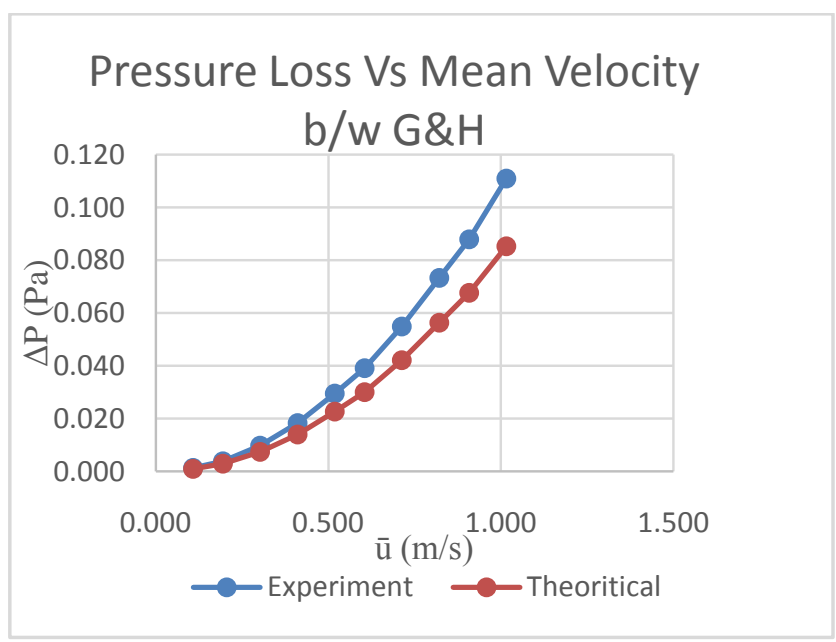

a)

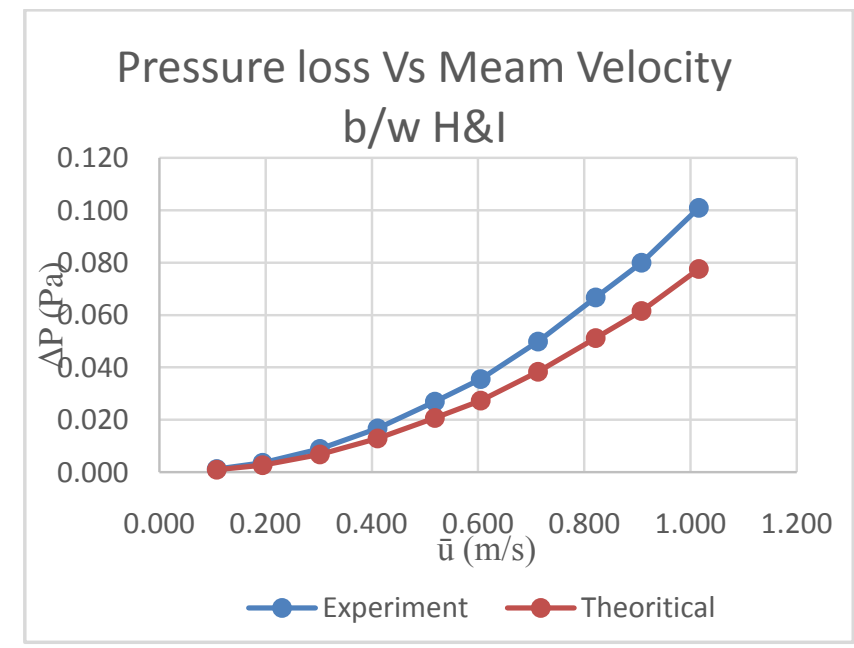

b)

Fig. 12 a, b. Comparison of experimental and theoretical total pressure drops verse mean velocities for test samples length $\mathrm{G}$ and $\mathrm{H}, \mathrm{H}$ and $\mathrm{I}$.

Similarly, it can be observed in Fig. 14 a, b that the result of the pressure drop between the experiment and theoretical prediction shows that the experiment is under-estimated by $23 \%$.

The percentage error estimation comparing the experiment and the theoretical values are shown in Fig. 13.

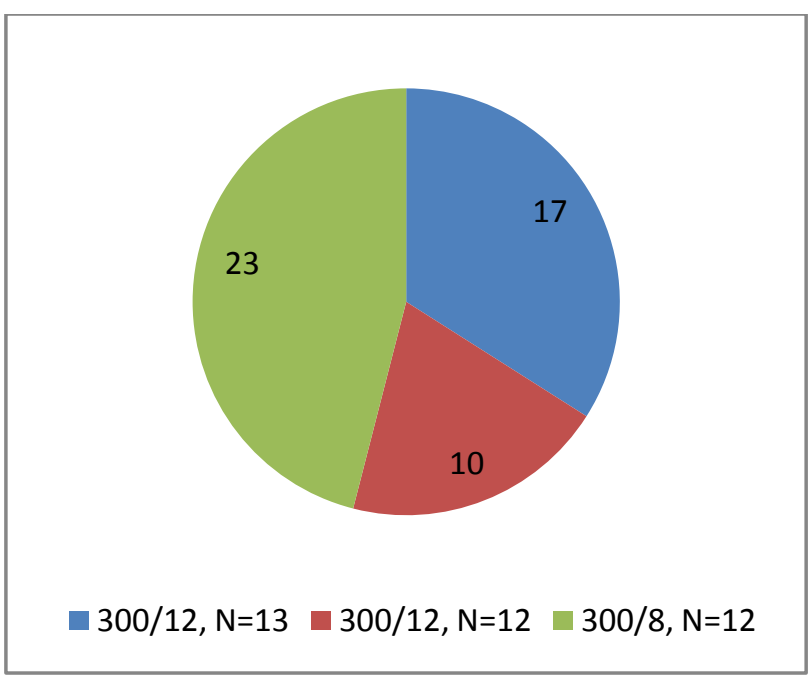

Fig. 13. \% error estimation plot for experimental and theoretical comparison

F. Effect of filter length on expansion/contraction losses The frictional losses were evaluated theoretically using the following equation and the result shown in Fig. 10.

$$
\Delta P_{\text {exp } / \text { Cont }}=\Delta P_{\text {Total }}-\Delta P_{F r}
$$

Where, $\Delta P_{F r}$ is frictional losses, and $\Delta P_{\text {Total }}$ is a total pressure losses.

The expansion/contraction pressure losses for the samples studied were compared in Fig. 14 a, b, and c. It can be observed that, the expansion/contraction pressure loss contribution is highest for $\mathrm{L}=250 \mathrm{~mm}$ in $\mathrm{N}=13(300 / 12)$ and contribute $55 \%$ of the entire losses. For $\mathrm{N}=12$, the losses are the same for $\mathrm{L}=305$ and $200 \mathrm{~mm}$ with $53 \%$ entire losses contributions. The loss is highest for $\mathrm{L}=200 \mathrm{~mm}$ and contribute $64 \%$ to the entire losses in sample 300/8. Theoretically, it is expected that after the friction losses are out of the picture all the remaining loss should be the same for all sample with the same OFA (Open Frontal Area). However, the friction loss estimation does not take into account the development of the boundary layer, therefore probably underestimates losses. Sample F is not expected as the lowest length is supposed to have the lowest pressure drop according to Darcy law.

This observation is promising in automotive application since in practice, space constrain has always been the challenge. 
World Journal of Innovative Research (WJIR)

ISSN: 2454-8236, Volume-5, Issue-3, September 2018 Pages 18-29

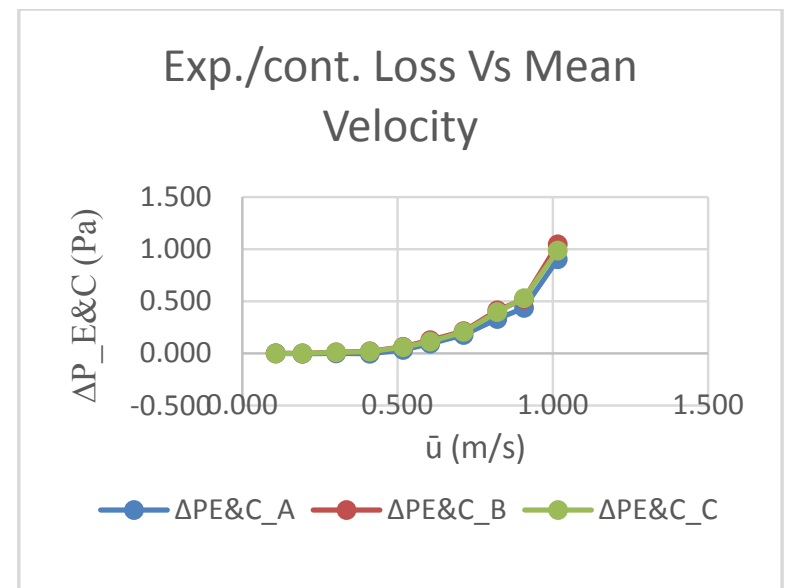

a)

\section{Exp./Cont. loss Vs Mean velocity}

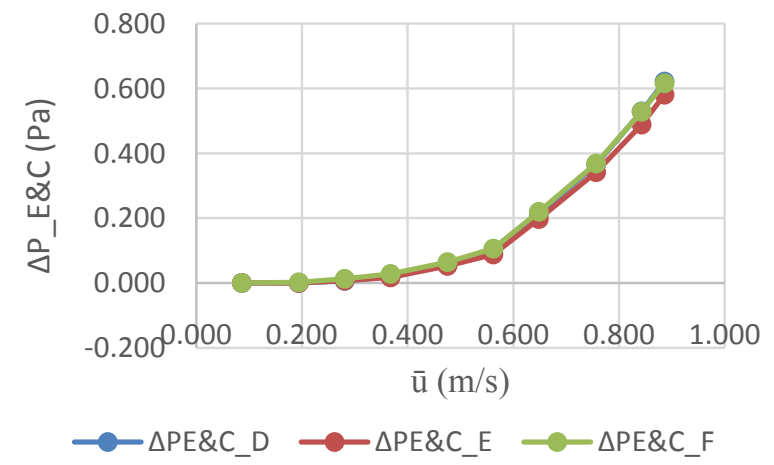

b)

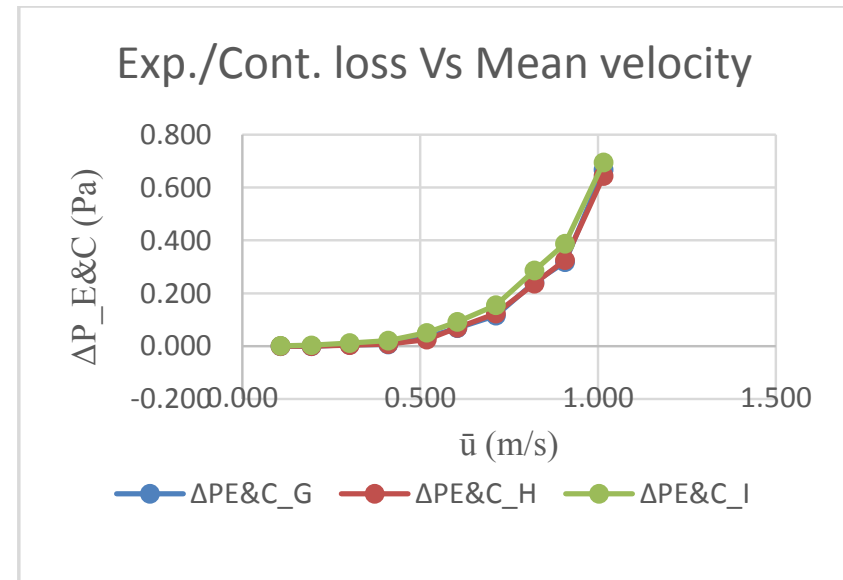

c)

Fig. 14a, b, c. plot of expansion/contraction pressure losses verse mean velocity for tested samples $(A, B, C, D, E, F, G$, $\mathrm{H}, \mathrm{I})$

\section{G. Pressure drop distribution in the channel}

It has been demonstrated in Fig.s8, 9 and 14 that, the pressure drops of the sample is sensitive to the change in the length of the samples. Therefore, a study was carried out on the pressure drop across the length of the test samples to understand the pattern of the pressure drop by using the different length of pressure tapings along the filters. The results are shown in the plot in Fig. $15 \mathrm{a}, \mathrm{b}$, and c. The highest Reynolds number of 2000 was chosen for this study as the experiment is more feasible at that Reynolds number,

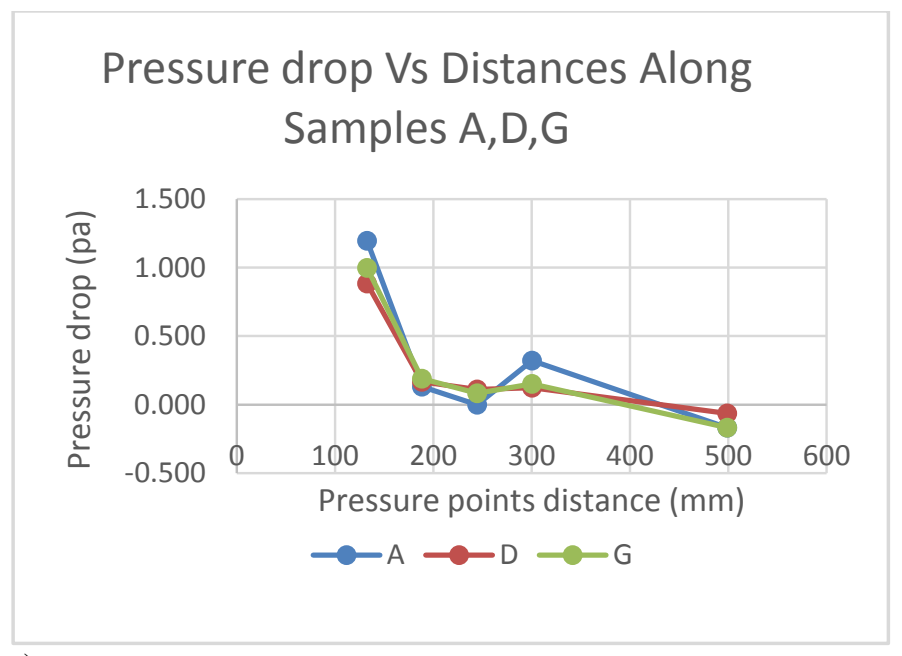

a)

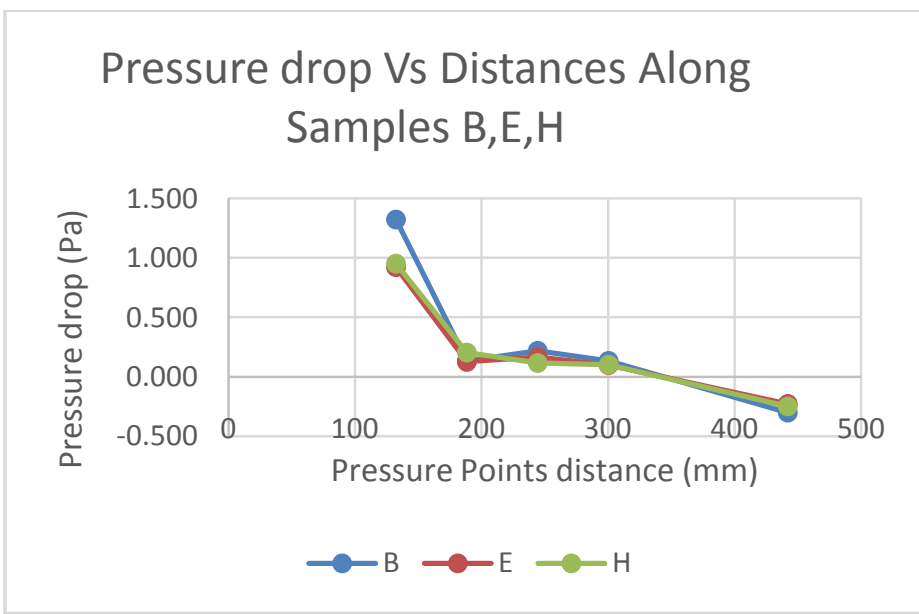

b)

\section{Pressure drop Vs Distances Along Samples C,F,I}

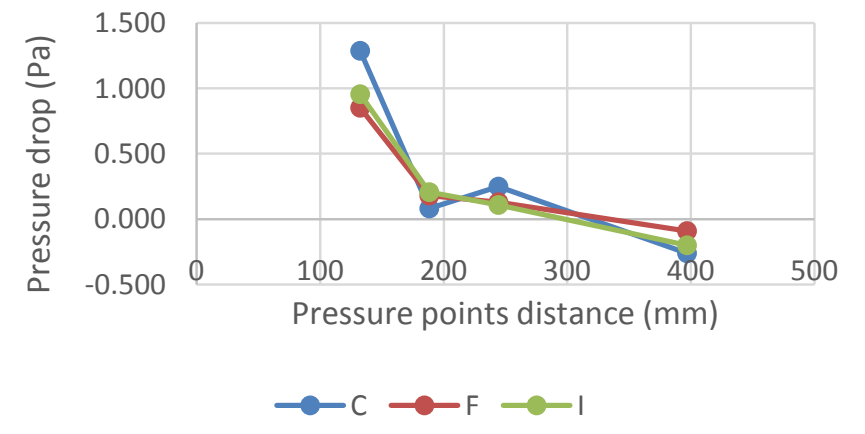

c)

Fig. $15 \mathrm{a}, \mathrm{b}, \mathrm{c}$. Plots of pressure drop and distances(x) for samples A, D, G $(\mathrm{L}=305 \mathrm{~mm}), \mathrm{B}, \mathrm{E}, \mathrm{H}(\mathrm{L}=250 \mathrm{~mm}), \mathrm{C}, \mathrm{F}, \mathrm{I}$ ( $\mathrm{L}=200 \mathrm{~mm})$

Fig. 15 shows pressure changes along the wall of the sample. The first pressure measurement is upstream of the sample, the last one downstream, while the other four measurements show wall pressure at the wall of one of the channels, as shown in Fig. 5. The pressure drop within the channel is primarily due to the entrance/outlet effect at the sample inlet/exit which led to contraction/expansion losses. 
As shown in Fig. 15a, the percentage ratio of expansion losses to contraction loses are approximately $2: 1$ for $\mathrm{L}=$ $305 \mathrm{~mm}$ and Pressure drop decreases from the beginning and recovered at vena contrata $(300 \mathrm{~mm})$ due to friction. Similarly, in Fig. 15 b, The percentage ratio of expansion losses to contraction loses are approximately $2.3: 1$ for $\mathrm{L}=$ $200 \mathrm{~mm}$ which has similarity in profile to $\mathrm{L}=305 \mathrm{~mm}$. considering Fig. 15c, The percentage ratio of expansion losses to contraction loses are approximately $2.5: 1$ for $\mathrm{L}=$ $250 \mathrm{~mm}$.

In general, these have a strong contribution to the total pressure losses and cannot be ignored.

\section{H. Effect of number of channels on expansion/contraction losses}

Similarly, the respond of expansion/contraction pressure loss contribution with respect to number of open channels $(\mathrm{N})$ and channel sizes were studied. The results are shown in Fig. 16.

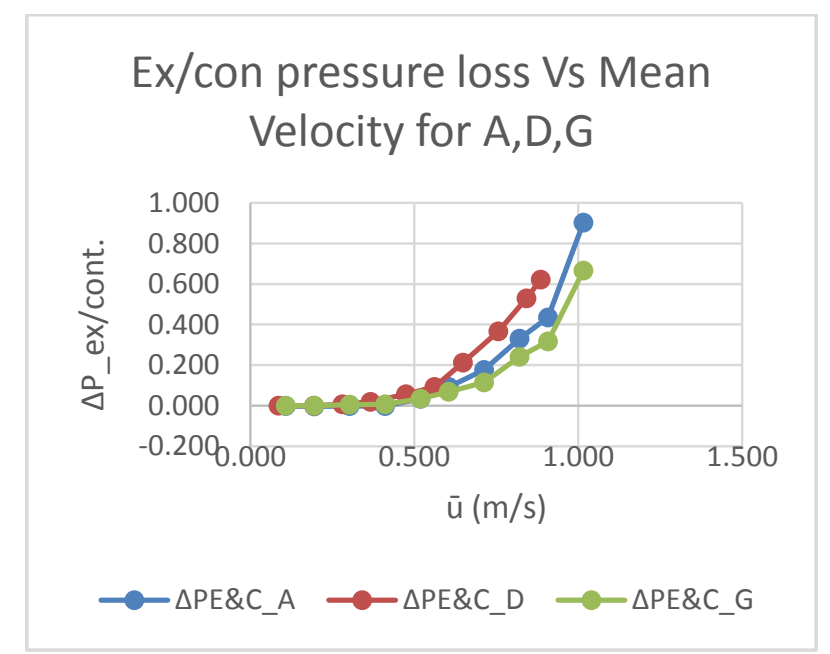

a)

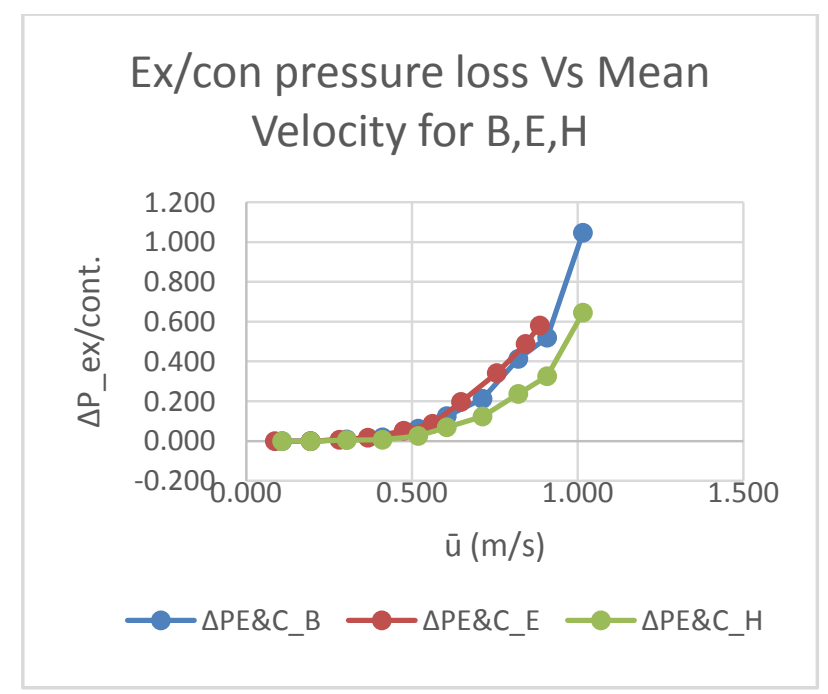

b)

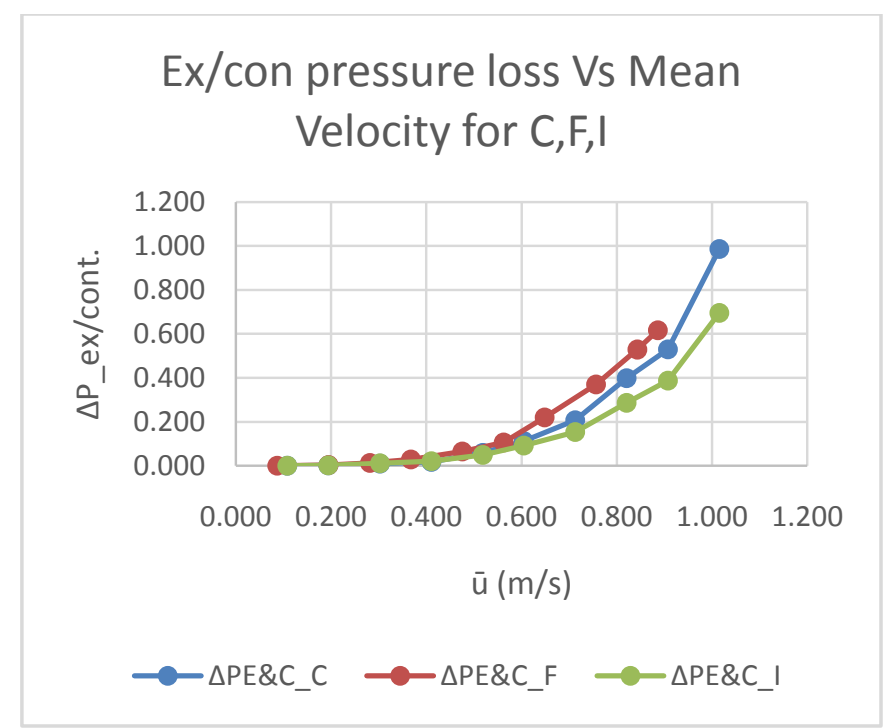

c)

Fig. 16 a, b, c. plots of expansion/contraction pressure loss contribution against mean velocity for samples A, D, G ( $\mathrm{L}=305 \mathrm{~mm}), \mathrm{B}, \mathrm{E}, \mathrm{H}(\mathrm{L}=250 \mathrm{~mm})$ and $\mathrm{C}, \mathrm{F}, \mathrm{I}(\mathrm{L}=200 \mathrm{~mm})$

It is observed across all the samples that, the contraction/expansion pressure loss contribution is higher for sample with higher number of open channels $(\mathrm{N}=13)$ across the lengths which is expected. Exp./cont. losses are lowest for sample $300 / 12(\mathrm{~N}=12)$ by $31 \% 42 \%$ and $37 \%$ for $\mathrm{L}=305$, 250 and 200 respectively at highest velocity.

In overall, it is observed in Fig. 16 that the pressure drops increase with increase in mean velocity.

The observations in Fig.14 and Fig. 16 has shown that, the expansion/contraction pressure losses are sensitive to the change in number of open channels, channel sizes, and the filter length within the length studied.

\section{Results for inertial loss coefficient}

Chart 1. Inertia loss contribution of the tested samples

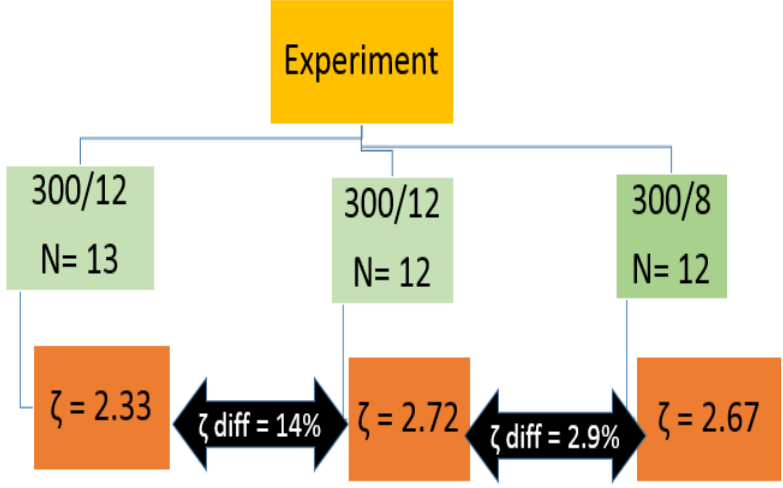

We observed that the inertial losses contribution by higher number of channel $(\mathrm{N}=13)$ is lesser than that of $\mathrm{N}=12$. These are non-negligible component to the total pressure drop of a filter.

\section{CONCLUSIONS}

The objective of this work was to investigate expansion/contraction pressure losses in gasoline particulate filters used within the flow field in the exhaust of automotive vehicles. The analysis was conducted and presented for several samples representing clean gasoline particulate 
World Journal of Innovative Research (WJIR)

ISSN: 2454-8236, Volume-5, Issue-3, September 2018 Pages 18-29

filters, discussed and validated experimentally. Comparison between theory and experimental measurements for the range of test samples were carried out. Even though, the filter particulate transport is changed by the gas flow and the mechanisms of coupled filtration, this analysis helps with tackling the issue of expansion and contraction pressure drops in gasoline particulate filters. This analysis does not capture transport flow mechanism in gasoline particulate traps or filtration losses. The observations here do not cover all areas such as thermal and mechanical integrity (filtration efficiency) as well as regeneration if it exists. The study presented here compared the values of inertia loss coefficient which is one of the key factors in contraction/expansion pressure drops with that in the literatures recorded in [1], [3], [11] and there are little variation. This type of study provides a quantitative picture of filter inlet and outlet transport processes as the flow approaches the test sample and exits the test sample.

The test sample for this study is not a wall flow filter and was not catalysed. Further work will be carried out on the wall flow test sample to represent filter and obtain the effect of the pressure drop the wall flow resistance will have on the expansion/ contraction pressure losses, as little or no work has been done on gasoline particulate filters in respect to that.

Highlight of conclusions can be drawn with the observations made in this work as:

* The available information in the literature [4],[7]; model used to predict the expansion /contraction pressure drops DPF has been used to predict the expansion/contraction pressure losses in gasoline particulate filters. The theory accounts for the contraction at the inlet and expansion at the outlet of the filter for the flow through the channels as the value of 2.8 inertial loss coefficients was obtained for $150 \mathrm{cpsi}$ with wall thickness of $1.6 \mathrm{~mm}$ which is quite close with this work result of inertial loss of 2.7 .

* The range of filter lengths, and flow rates were used to validate the model experimentally. Wall thickness, number of open channels were also studied and included in validating the model. A close observation of the parameter study shows that, the contraction/expansion pressure drops along the filter is sensitive to the filter length (decreases as the filter length is reduced from $305 \mathrm{~mm}$ to $250 \mathrm{~mm}$ and increases as it is further reduced to $200 \mathrm{~mm}$ ) as well as the number of channels in the filter (increases with increase number of channels).

* Exit expansion losses are approximately 2.5 times higher than inlet contraction losses compare to '2 times higher' prediction in [12].

- Exp./contr. Contribution to the total losses are: $55 \%, 53 \%$ for $\mathrm{N}=13$ and 12 respectively for sample $300 / 12$ and $64 \%$ for sample $300 / 8$.

\section{REFERENCES}

[1] Konstandopoulus, A.G., Athanasios, G., Evangelos, S. and Mansour, M. (2001) "'Inertial Contributions to the Pressure Drop of Diesel Particulate Filters', SAE Technical Paper Series

[2] Van Nieuwstadt, M. and Ulrey, J. (2017) "Control Strategies for Gasoline Particulate Filters". SAE Technical Paper Series

[3] Dr.Wesam Al Madhoun(2017) Control of Particulate Matter [Online] available from <http://slideplayer.com/slide/6042096/> [13 May 2017]

[4] Konstandopoulus, A.G. and Athanasios, G. (2003) 'Flow Resistance Descriptors for Diesel Particulate Filters: Definitions, Measurements and Testing', SAE Technical Paper Series

[5] John, F., Janusz, A., John, A., and Lynne, B. (2011) Fluid Mechanics. $6^{\text {th }}$ edn. London: pearson

[6] Munson, B., Young, D., Okiishi, T. (2006) Fundamental of Fluid Mechanics. Hoboken, NJ: Whiley

[7] Yunus, O., Haluk E. (2016) On the pressure drop of wall-flow diesel particulate filter [online] available from <http://pub.dega-akustik.de/IN2016/data/articles/000792.pdf>[31 May 2017]

[8] Van Nieuwstadt, M. and Ulrey, J. (2017) "Control Strategies for Gasoline Particulate Filters". SAE Technical Paper Series

[9] Konstandopoulos, A., Kostoglou, M. and Housiada, P. (2001) "Spatial Non-Uniformities in Diesel Particulate Trap Regeneration". SAE Technical Paper Series

[10] Mogaka, Z., Wong, V. and Shahed, S. (1982) "Performance And Regeneration Characteristics Of A Cellular Ceramic Diesel Particulate Trap". SAE Technical Paper Series

[11] Athanasios, G. Konstandopoulus, A.G., Kostoglou, M., Vlachos, N. and Kladopoulou, E. (2005) 'Progress in Diesel Particulate Filter Simulation'. SAE Technical Paper Series

[12] Masoudi, M., Heibel, A. and Then, P. (2000) "Predicting Pressure Drop Of Wall-Flow Diesel Particulate Filters - Theory And Experiment". SAE Technical Paper Series

[13] Konstandopoulos, A. and Johnson, J. (1989) "Wall-Flow Diesel Particulate Filters-Their Pressure Drop and Collection Efficiency". SAE Technical Paper Series

\section{APPENDIXES}

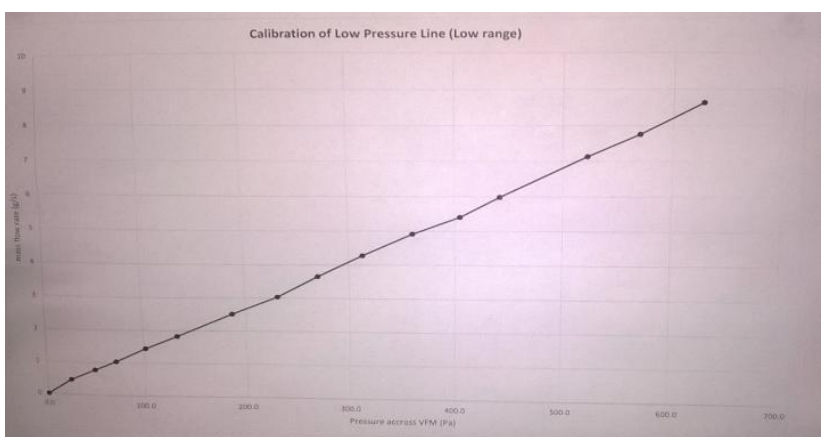

A1. Graph of Low pressure line calibration used.

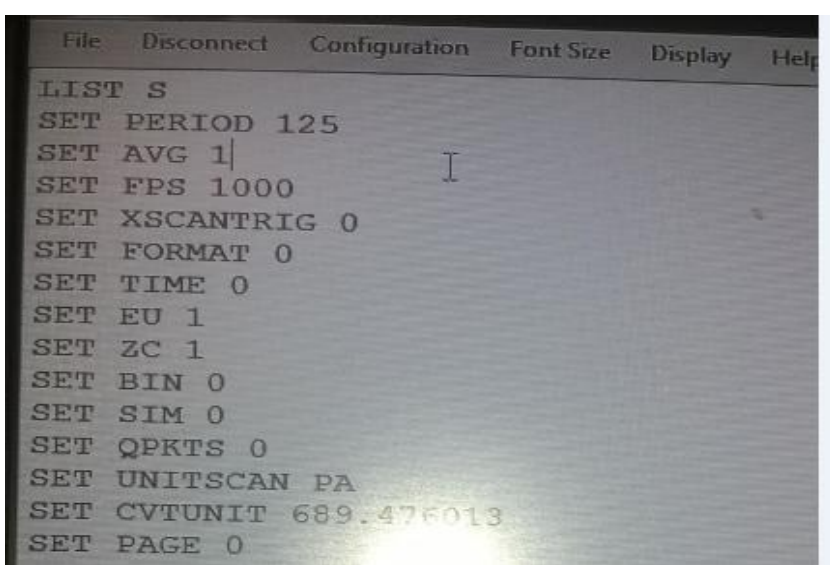

A2. Software setup for experimental measurements. 


\section{Gasoline Particulate Filter (GPF) Expansion/Contraction Pressure Losses}

\section{PERSONAL PROFILE}

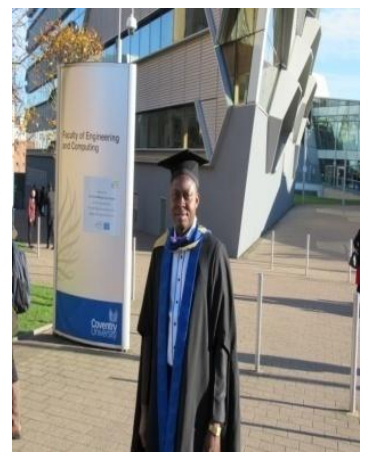

Abel Ojimah did his masters in automotive engineering at Coventry University, United Kingdom in the year 2017. During maters programme, researches were done on gasoline particulate filters looking at the expansion/contraction pressure losses, formula 1 vehicle, modernizing the aerodynamics shape to achieve the target lift to drag ratio, specification of 2004 model of ford focus I.C engine was used to design an electric motor and bench marked with Artemus driving cycle.All this projects were successfully completed. A lecturer at Kogi State Polytechnic Lokoja, Nigeria from 2013 till date. My B.Eng is in the area of mechanical engineering where project 'control of corrosion in a steel reinforced concrete, using groundnut oil and palm kernel oil' was carried out successfully and the result was encouraging as they oils bothserves as inhibitor to corrosion. A member of a professional bodies 'The Nigerian Society of Engineers (NSE) and Council for The Regulation of Engineering in Nigeria (COREN)' 